\title{
Silencing of SARS-CoV-2 with modified siRNA-peptide dendrimer formulation
}

Musa Khaitov $^{1}$, Alexandra Nikonova ${ }^{2}$, Igor Shilovskiy ${ }^{1}$, Ksenia Kozhikhova ${ }^{1}$, Ilya Kofiadi

${ }^{1}$, Lyudmila Vishnyakova ${ }^{1}$, Aleksandr Nikolskii ${ }^{1}$, Pia Gattinger ${ }^{3}$, Valeria Kovchina ${ }^{1}$, Ekaterina Barvinskaya ${ }^{1}$, Kirill Yumashev ${ }^{1}$, Valeriy Smirnov ${ }^{1}$, Artem Maerle ${ }^{1}$, Ivan Kozlov ${ }^{1}$, Artem Shatilov ${ }^{1}$, Anastasia Timofeeva ${ }^{1}$, Sergey Andreev ${ }^{1}$, Olesya Koloskova ${ }^{1}$, Ilya Sergeev ${ }^{1}$, Dmitry Trofimov ${ }^{1}$, Alexander Martynov ${ }^{1}$, Igor Berzin ${ }^{4}$, Vladimir Gushchin $^{5}$, Aleksey Kovalchuk ${ }^{6}$, Sergei Borisevich ${ }^{6}$, Rudolf Valenta ${ }^{1}$, Rakhim Khaitov ${ }^{1}$, and Veronica Skvortsova ${ }^{4}$

${ }^{1}$ NRC Institute of Immunology FMBA Russia

${ }^{2} \mathrm{NRC}$ Institute of Immunology

${ }^{3}$ Medical University of Vienna

${ }^{4}$ Federal Medico-biological Agency of Russia (FMBA Russia)

${ }^{5}$ Federal State Budget Institution "National Research Centre for Epidemiology and Microbiology named after Honorary Academician N. F. Gamaleya" of the Ministry of Health of the Russian Federation

${ }^{6} 48$ Central Research Institute of the Ministry of Defense of the Russian Federation

February 17, 2021

\begin{abstract}
Background. First vaccines for prevention of Coronavirus disease 2019 (COVID-19) are becoming available but there is a huge and unmet need for specific forms of treatment. In this study we aimed to evaluate the potent anti-SARS-CoV-2 effect of siRNA both in vitro and in vivo. Methods. To identify most effective molecule out of a panel of 15 in silico designed siRNAs, an in vitro screening system based on vectors expressing SARS-CoV-2 genes fused with the firefly luciferase reporter gene and SARS-CoV-2-infected cells was used. The most potent siRNA, siR-7, was modified by Locked nucleic acids (LNAs) to obtain siR-7-EM with increased stability and was formulated with the peptide dendrimer KK-46 for enhancing cellular uptake to allow topical application by inhalation of the final formulation - siR-7-EM/KK-46. Using the Syrian Hamster model for SARS-CoV-2 infection the antiviral capacity of siR-7-EM/KK-46 complex was evaluated. Results. We identified the siRNA, siR-7, targeting SARS-CoV-2 RNA-dependent RNA polymerase (RdRp) as the most efficient siRNA inhibiting viral replication in vitro. Moreover, we have shown that LNA-modification and complexation with the designed peptide dendrimer enhanced the antiviral capacity of siR-7 in vitro. We demonstrated significant reduction of virus titer and total lung inflammation in the animals exposed by inhalation of siR-7-EM/KK-46 in vivo. Conclusions. Thus, we developed a therapeutic strategy for COVID-19 based on inhalation of a modified siRNA-peptide dendrimer formulation.
\end{abstract}

\section{Silencing of SARS-CoV-2 with modified siRNA-peptide dendrimer formulation} Short title: Anti-SARS-CoV-2 siRNA-peptide dendrimer formulation

Musa Khaitov $^{1 *}$, Alexandra Nikonova ${ }^{1,2}$, Igor Shilovskiy ${ }^{1}$, Ksenia Kozhikhova ${ }^{1}$, Ilya Kofiadi ${ }^{1}$, Lyudmila Vishnyakova $^{1}$, Alexander Nikolsky ${ }^{1}$, Pia Gattinger ${ }^{3}$, Valeria Kovchina ${ }^{1}$, Ekaterina Barvinskaya ${ }^{1}$, Kirill Yumashev $^{1}$, Valeriy Smirnov ${ }^{1}$, Artem Maerle ${ }^{1}$, Ivan Kozlov ${ }^{1}$, Artem Shatilov ${ }^{1}$, Anastasia Timofeeva ${ }^{1}$, Sergey 
Andreev $^{1}$, Olesya Koloskova ${ }^{1}$, Ilya Sergeev ${ }^{1}$, Dmitriy Trofimov ${ }^{1}$, Alexander Martynov, Igor Berzin ${ }^{4}$, Vladimir Gushchin $^{5}$, Aleksey Kovalchuk ${ }^{6}$, Sergei Borisevich ${ }^{6}$, Rudolf Valenta ${ }^{1,3}$, Rakhim Khaitov ${ }^{1}$ and Veronica Skvortsova ${ }^{4}$

${ }^{1}$ NRC Institute of Immunology FMBA, Moscow, Russia

${ }^{2}$ Mechnikov Research Institute for Vaccines and Sera, Moscow, Russia

${ }^{3}$ Medical University of Vienna, Vienna, Austria

${ }^{4}$ Federal Medico-biological Agency of Russia (FMBA Russia)

${ }^{5}$ Federal State Budget Institution "National Research Centre for Epidemiology and Microbiology named after Honorary Academician N. F. Gamaleya" of the Ministry of Health of the Russian Federation, Moscow, Russia

${ }^{6} 48$ Central Research Institute of the Ministry of Defense of the Russian Federation, Moscow, Russia

* Corresponding author

\section{Acknowledgements}

This study was funded by Federal Medico-biological Agency of Russia. We are grateful to Prof. Andrew Fire, Stanford University for having critically read our manuscript.

Word count: 5690

Abstract

Background . First vaccines for prevention of Coronavirus disease 2019 (COVID-19) are becoming available but there is a huge and unmet need for specific forms of treatment. In this study we aimed to evaluate the potent anti-SARS-CoV-2 effect of siRNA both in vitroand in vivo .

Methods. To identify most effective molecule out of a panel of 15 in silico designed siRNAs, an in vitro screening system based on vectors expressing SARS-CoV-2 genes fused with the firefly luciferase reporter gene and SARS-CoV-2-infected cells was used. The most potent siRNA, siR-7, was modified by Locked nucleic acids (LNAs) to obtain siR-7-EM with increased stability and was formulated with the peptide dendrimer KK-46 for enhancing cellular uptake to allow topical application by inhalation of the final formulation siR-7-EM/KK-46. Using the Syrian Hamster model for SARS-CoV-2 infection the antiviral capacity of siR-7-EM/KK-46 complex was evaluated.

Results. We identified the siRNA, siR-7, targeting SARS-CoV-2 RNA-dependent RNA polymerase (RdRp) as the most efficient siRNA inhibiting viral replication in vitro. Moreover, we have shown that LNAmodification and complexation with the designed peptide dendrimer enhanced the antiviral capacity of siR-7 in vitro. We demonstrated significant reduction of virus titer and total lung inflammation in the animals exposed by inhalation of siR-7-EM/KK-46in vivo .

Conclusions. Thus, we developed a therapeutic strategy for COVID-19 based on inhalation of a modified siRNA-peptide dendrimer formulation.

Key words: COVID-19, LNA, peptide dendrimers, SARS-CoV-2, siRNA.

\section{Introduction}

In December 2019, an outbreak of severe acute respiratory infections was reported in the Chinese city of Wuhan. In the meantime, the disease named COVID-19 (Corona Virus Disease-19) has flooded the globe and became the deadliest respiratory disease pandemic since 1918 when the Spanish influenza pandemic killed more than 50 million people $(1,2)$. The culprit of the current COVID-19 pandemic outbreak is the novel coronavirus $(\mathrm{CoV})$ which was named as severe acute respiratory syndrome coronavirus 2 (SARS-CoV-2) by the International Committee on Taxonomy of Viruses (ICTV). SARS-CoV-2 such as SARS-CoV and MERS-CoV 
which all can cause severe respiratory illness belong to the closely related $\beta$-corona viruses(3) and have originated as human pathogens by animal-to-human-host switching(4). The two SARS viruses are derived from viruses enzootic in bats for which a rich reservoir exists in Asian countries and in particular in China(5). As of January 27, 2021, there are $>100$ million confirmed cases and $>2$ million related deaths related to COVID19 according to the Johns Hopkins Coronavirus Resource Center (https://coronavirus.jhu.edu/map.html). Currently, multiple vaccine candidates have entered into clinical trials, some of them have already been approved by health authorities and recently vaccination has been started in several countries (6-9).

However, in addition to prophylactic vaccines SARS-CoV-2-specific therapies for treatment of infected patients are urgently needed. Accordingly, several antiviral drugs, among them remdesivir, hydroxychloroquine, lopinavir and interferons, have been evaluated for treatment of COVID-19 but so far with limited clinical success $(10,11)$. Convalescent plasma treatment is another possibility for treatment of severe COVID-19(12) and achieved FDA approval for treatment of critically ill patients but there are limitations to its production(13). In addition, first monoclonal SARS-CoV-2-specific antibodies have been developed, showed first promising results in experimental animal models(14) and reduced viral loads in patients(15). Therefore, a huge unmet need for SARS-CoV-2-specific treatment strategies remains.

The SARS-CoV-2 viral genome is a single-stranded positive RNA (+ssRNA) of almost $30 \mathrm{~kb}$, encoding at least 5 open reading frames (ORFs). The first ORF (ORF1a/b) occupies about $70 \%$ of the entire genome and encodes 16 nonstructural proteins (nsp1-16). The remaining 30\% of the genome encodes 4 major structural proteins necessary for virion assembly: spike (S), membrane $(\mathrm{M})$, envelope (E), nucleocapsid (N)(16-18).

Gene expression in general and viral gene expression in infectious diseases can be suppressed through the mechanism of RNA interference (RNAi) for therapeutic purposes(19-23). The RNAi approach is based on negative regulation of gene expression at the post-transcriptional level and therefore highly specific $(24,25)$. Hence, the main advantage of the RNAi strategy over most other therapeutic approaches is its specificity but the technology has also limitations among them how to enhance specific targeting of and efficient transportation into infected cells.

In this study we screened a panel of SARS-CoV-2-specific siRNAs for their potential to silence SARS-CoV2 gene expression. The most potent silencing siRNA was then modified to enhance siRNA stability and formulated with a novel non-toxic peptide dendrimer KK-46 as vehicle for efficient siRNA delivery into the target cells. Finally we show in anin vivo model of SARS-CoV-2 infection in Syrian hamsters(26) that topical treatment by inhalation of the modified siRNA-peptide dendrimer formulation has the potential to reduce viral replication and to ameliorate SARS-CoV-2-induced lung inflammation.

\section{Materials and Methods}

\section{Plasmid constructs and design of siRNA}

The primary screening of siRNAs was performed in vitro using vectors expressing viral genes fused with the firefly luciferase reporter gene. Three vectors expressing full-size genes and gene fragments of SARS-CoV-2 (NCBI RefSeq NC_045512.2) leader protein NSP1 (540 bp), RdRp RNA-dependent RNA polymerase (2796 bp) and nucleocapsid protein N (1260 bp) were designed (pVAX-LP-IRES-LUC, pRdRp-full and pVAXN-IRES-LUC, respectively) (Fig.1). Plasmid pVAX-1 (Thermo Fisher Scientific, Waltham, Massachusetts, USA) ensuring stable protein expression in eukaryotic cells, was used as expression vector. The expression plasmids containing virus-specific inserts were synthesized as three bicistronic expression plasmids containing IRES fragment (Takara Bio USA, Mountain View, California, USA) (Fig. 1a-c). The vectors allow mRNA transcription of target (RdRp or N or NSP1) and reporter (Luc) genes under a single CMV promoter followed by translation of the target and reporter proteins. A single RNA-transcript assures comparable expression of both genes.

In total 15 siRNA duplexes targeting NSP1, RdRp and N proteins of SARS-CoV-2 (Fig. 1d) were designed in silico and synthesized by "DNA-technology" company (Moscow, Russia) (sequences are described in a patent application (27)). siRNA against firefly luciferase (siLuc)(28) and GFP (sense strand: 5'- 
CAAGCUGACCCUGAAGUUCtt-3') were used as controls.

Co-transfection of HEp-2 cells with plasmid constructs and siRNAs

HEp-2 cells (ATCC@ Number: CCL-23) were cultivated with $10 \%$ fetal bovine serum (FBS) (HyClone, U.S.) and $1 \%$ penicillin/streptomycin (PS; PanEco, Russia) in Dulbecco's modified Eagle's medium (DMEM; PanEco, Russia). The cells were seeded into 24 -well plates at a concentration of $10^{5}$ cells/well in $0.5 \mathrm{~mL}$ of media and incubated at $37 \mathrm{degC}$ with $5 \% \mathrm{CO}_{2}$ for $12-24 \mathrm{~h}$. The cells were consistently co-transfected with each of the plasmid constructs $(0.25 \mu \mathrm{g} /$ well $)$ pRdRp-full, pVAX-N-IRES-LUC and pVAX-LP-IRESLUC/Lipofectamine $3000(0.5 \mu \mathrm{L} /$ well $)$ complexes and then in 30 minutes with each of the 15 different siRNAs $(0.75 \mu \mathrm{g} /$ well $)$ with Lipofectamine 3000 (1.5 $\mu \mathrm{L} /$ well). In both cases complexes with Lipofectamine 3000 were made in serum-free Opti-MEM media (Gibco) according to the manufacturer's protocol. After four hours, media with complexes were replaced with fresh DMEM. Then, after $24 \mathrm{~h}$ cells were harvested, lysed, and assayed for firefly luciferase activity using the Luciferase Assay System (Promega) according to the manufacturer's instructions. Cells transfected with siLuc (described previously(28)) and siGFP were used as a positive and negative control, respectively.

Synthesis, purification and characterization of the peptide dendrimer KK-46

The design of the cationic dendrimeric peptide KK-46 for intracellular delivery of siRNA was based on in silico calculation of the molecular properties (Chemsketch software, Dock Prep software, PyMOL software) to achieve an optimal range of positive charge and amphiphilicity for cell penetration and RNA-binding. The positive charge was attributable to the use of arginine and histidine residues for the N-terminal ends of the peptide branches (the basic sequences are described previously(29)). The peptide for this study was de novo synthesized using automatic solid-phase peptide synthesis with Fmoc-protection strategy of $\alpha$-amino groups (PS3 Peptide Synthesizer, Gyros Protein Technologies, Tucson, USA). The purification of the peptide was performed by means of preparative reverse-phase high performance liquid chromatography with ODS column (octadecylsilyl groups chemically bonded to a silica gel carrier) and 0.1\% TFA and acetonitrile as the mobile phase. The peptide molecular mass was confirmed by matrix assisted laser desorption/ ionization time-offlight (Bruker Daltonics Microflex LT MALDI-TOF, Bruker Corporation, Billerica, USA). The peptide was tested for its ability to inhibit the binding of RBD to ACE2 using a molecular interaction assay(30).

Transfection of HEp-2 cells with pGL-3/KK-46 complexes

The HEp-2 cells were propagated as described above. Cells were transfected with the pGL3 Luciferase Reporter Vector (Promega) $(0.5 \mu \mathrm{g} /$ well) in complexes with peptide dendrimer KK-46. In these experiments several weight ratios of KK-46 and vector (5:1,12.5:1, 20:1, 25:1, 50:1, 100:1 $\mu \mathrm{g}$ KK-46: $\mu \mathrm{g}$ pGL3) were used to transfect the cells. Commercial Lipofectamine 3000 was used as positive control. The transfection protocol and assays were performed as described above.

Viral Stocks

The SARS-CoV-2 strain PMVL-1 (GISAID Number EPI_ISL_421275) was propagated and titrated in Vero E6 cells (ATCC ${ }^{\circledR}$ Number: CRL-1586 ${ }^{\mathrm{TM}}$ ) to determine $\mathrm{TCID}_{50} / \mathrm{mL}$ (50\% tissue culture infectivity dose). This virus was used for experiments in vitro. The SARS-CoV-2 strain B was grown in Vero C1008 cells (ATCC\&) CRL-1586) and used for in vivo experiments. SARS-CoV-2 strain B was titrated on Vero C1008 cells by plaque assay to determine the number of plaque forming units (PFU) as described(31). Viral stocks were used at $1.0 \times 10^{5} \mathrm{TCID}_{50} / \mathrm{mL}$ and $1.0 \times 10^{6} \mathrm{PFU} / \mathrm{mL}$ for strain PMVL-1 and strain B of SARS-CoV-2, respectively.

Transfection of antiviral siRNA/siLNA with Lipofectamine 3000 or peptide dendrimer KK-46

Vero E6 cells $\left(\right.$ ATCC $^{(\mathrm{r})}$ Number: CRL-1586 ${ }^{\mathrm{TM}}$ ) were cultivated with $5 \%$ of FBS (HyClone, Logan, UT, USA) and $1 \%$ PS in DMEM (PanEco, Moscow, Russia). The cells were seeded into 24-well plates at a concentration of $10^{5}$ cells/well in $0.5 \mathrm{~mL}$ of medium and incubated at $37 \mathrm{degC}, 5 \% \mathrm{CO}_{2}$ for $12-24 \mathrm{~h}$. 
The medium was replaced with FBS-free Opti-MEM (Gibco, USA). Aliquots of $100 \mu \mathrm{L}$ containing $0.5 \mu \mathrm{g}$ of specific or non-specific siRNAs, $1.5 \mu \mathrm{L}$ of Lipofectamine3000 (Invitrogen) in Opti-MEM were added to VeroE6 cells. After four hours, complexes were removed, and cells were infected with SARS-CoV-2 at a multiplicity of infection (MOI) of 0.0001 and incubated for 1 hour at $37^{\circ} \mathrm{C}, 5 \% \mathrm{CO}_{2}$. Cells were washed and non-adherent virus was removed and re-suspended in the fresh media. Cell culture supernatants and RNA lysates were harvested at times indicated and stored at $-80{ }^{\circ} \mathrm{C}$.

The same procedure was used for transfection with siRNA/KK-46 complexes. The only exception was the amount of the components. Three increasing concentrations of complexes 21,42 and $84 \mu \mathrm{g} /$ per well which included the sums of KK-46+siRNA/siLNA, $\mu \mathrm{g}$ : 20+1, 40+2 and 80+4, respectively (20:1 weight ratio) were used. Unspecific siRNA targeting the gene of firefly luciferase (siLuc) and SARS-CoV-2 infected cells were used as negative controls.

\section{RNA extraction and quantitative RT-PCR}

RNA was extracted from cell culture supernatants and cells lysates using the ExtractRNA Reagent (Eurogen, Moscow, Russia) following the manufacturer's instructions. Reverse transcription and PCR amplification were carried out with a one-step SARS-CoV-2 FRT kit (N.F. Gamaleya NRCEM, Moscow, Russia) according to the manufacturer's instructions. The primers and probes were designed to target the gene coding NSP1 (Leader Protein) of SARS-CoV-2 (Fig.1d). The conditions of the one-step RT-qPCR reaction were as follows: $50^{\circ} \mathrm{C}$ for $15 \mathrm{~min}, 95^{\circ} \mathrm{C}$ for $5 \mathrm{~min}$, followed by 45 cycles of $95^{\circ} \mathrm{C}$ for $10 \mathrm{~s}$ and $55^{\circ} \mathrm{C}$ for $1 \mathrm{~min}$. The number of copies of viral RNA was calculated using a standard curve generated by amplification of plasmid DNA template.

\section{Serum stability}

To increase stability, we incorporated LNA (locked nucleic acid)-modifications to the 3' ends of the siR-7 guide and passenger strands. The LNA-modified siR-7-EM (siLNA) was synthesized by "DNA-technology" company (Moscow, Russia).

Duplexes of siRNA (siR-7) and siLNA (siR-7-EM) $(3 \mu \mathrm{g})$ were incubated at $37^{\circ} \mathrm{C}$ in $50 \%$ fetal bovine serum (Invitrogen) diluted in phosphate buffered saline for $264 \mathrm{~h}$. Aliquots of $10 \mu \mathrm{g}$ were withdrawn at indicated time points and stored at $-20^{\circ} \mathrm{C}$. Samples were then subjected to electrophoresis in $1.5 \%$ agarose gel, stained with Ethidium Bromide and quantified by Imagequant software (Amersham Biosciences, Uppsala, Sweden).

\section{Experiments in vivo}

Experiments with animals were carried out in accordance with the EU Directive 2010/63/EU for animal experiments. The Syrian hamsters (females, 4-5 weeks of age, $40-60 \mathrm{~g}$ weight) were used to assess the antiviral activity of siR-7-EM (siLNA)/KK-46 complexes in vivo .

In the first set of in vivo experiments we aimed to find the optimal concentration of the siR-7-EM/KK-46 complexes. Six groups of animals $(\mathrm{N}=10)$ were formed. Five out of the six groups were intranasally infected with $10^{5} \mathrm{PFU} /$ animal of SARS-CoV-2 strain B on day 0. On the same day (one hour after infection) and day 1 infected animals were exposed to a siR-7-EM/KK-46 aerosol at three increasing doses: 0.7, 1.96 or $5.6 \mathrm{mg} / \mathrm{kg}$. The hamsters were anesthetized and placed in an inhalation exposure chamber. Aerosols were formed using a conventional Xiaomi Andon VP-M3A Micro Mesh Nebulizer. The positive control group received Hydroxychloroquine resuspended in a 1\% starch solution orally (1 hour after infection, a dose of $3.8 \mathrm{mg} /$ animal and then daily for 6 days post infection with $1.5 \mathrm{mg} /$ animal). A virus-only control group included animals infected with SARS-CoV-2. Group "Intact" did not receive any treatment and served as a negative control. Five animals from each group were sacrificed at day 2 after infection, lungs were removed. Macroscopic evaluation and scoring of the histopathology lesions of the lung were performed. The histopathological changes were graded according to a modified semiquantitative scoring system by a blinded investigator (none, 0; mild, 1.0; moderate, 2.0; or severe, 3.0). The right lobe of the lung was homogenated and the viral titer was assessed by plaque assay to determine the number of PFU as described(31). Five 
animals left in each group were exposed to the siR-7-EM/KK-46 aerosol at days 3, 4, 5 and were sacrificed at day 6 after infection. Lungs were removed and processed as described above.

The second series of in vivo experiments were performed according to the same scheme with two exceptions. First, we exposed animals to $0.175,0.35$ and $1.0 \mathrm{mg} / \mathrm{kg}$ of siR-7-EM/KK-46 aerosol twice a day with two hours interval to yield a daily dose of the antiviral complexes of $0.35,0.7$ and $2.0 \mathrm{mg} / \mathrm{kg}$, respectively. Second, the control group of animals received orally Favipiravir (within 1 hour after infection, a dose of 1.2 $\mathrm{mg} /$ animal was administered twice a day, and then daily for 6 days post infection $0.4 \mathrm{mg} /$ animal were given twice a day).

Statistical analysis

The Shapiro-Wilk test for normality was performed. Data were presented as means + s.e.m for parametric analyses and as medians + s.d. for nonparametric analyses, as indicated in the figure legends. Statistical analyses were performed using Prism 8 (GraphPad Software). For normally distributed data we performed ordinary one-way ANOVA or one-way repeated measures ANOVA with Tukey's or Dunnetts's post hoc tests, respectively, for multiple comparisons to determine differences between groups, or if not normally distributed the Kruskal-Wallis test followed by post hoc testing (if the Kruskal-Wallis was significant) using un-paired Mann-Whitney U tests was performed, as mentioned in the respective figure legends. Data were accepted as significantly different when $\mathrm{P}<0.05$.

Results

Screening of siRNAs for silencing of SARS-CoV-2 genes by bioluminescence assay

To determine the silencing activity of 15 anti-SARS-CoV-2 siRNAsin vitro, we constructed plasmids pRdRpfull, pVAX-N-IRES-LUC and pVAX-LP-IRES-LUC simultaneously expressing SARS-CoV-2 genes RdRp (RNA dependent RNA polymerase), N (nucleocapsid), LP (leader protein), respectively, and the reporter gene of firefly luciferase. Hep-2 cells were co-transfected with vectors pRdRp-full, pVAX-N-IRES-LUC and pVAX-LP-IRES-LUC and 15 different siRNA variants to evaluate their knockdown activity. siRNA against luciferase (siLuc) and GFP (siGFP) were used as a positive and negative control, respectively. Eight of the 15 designed specific siRNAs significantly reduced luciferase activity in vitro with various levels of efficacy compared to non-specific siGFP and/or cells, transfected with plasmid only (table 1, fig. 2). As indicated in table 1: siLP-1, siN-3, siN-4, siN-5, siR-6, siR-7, siR-11 and siR-13 significantly decreased the level of luminescence as follows, \%: $82.43(\mathrm{P}<0.05), 74.53(\mathrm{P}<0.01), 69.21(\mathrm{P}<0.05), 84.03(\mathrm{P}<0.01), 67.95(\mathrm{P}<0.05)$, $88.28(\mathrm{P}<0.01), 68.77(\mathrm{P}=0.0519)$ and $65.17(\mathrm{P}=0.0519)$, respectively, compared with cells transfected with plasmid only and $84.67(\mathrm{P}<0.05), 76.35(\mathrm{P}<0.05), 64.88(\mathrm{P}=0.0568), 81.78(\mathrm{P}<0.05), 63.45(\mathrm{P}=0.0666), 89.12$ $(\mathrm{P}<0.01), 71 \quad(\mathrm{P}<0.05)$ and $67.66(\mathrm{P}<0.05)$, respectively, compared to cells transfected with non-specific siGFP. Control siLuc significantly reduced expression of firefly luciferase as follows, \%: $70.24(\mathrm{P}<0.001)$, $77.69(\mathrm{P}<0.05)$ and $53.1(\mathrm{NS})$ compared to cells transfected with pRdRp-full, pVAX-N-IRES-LUC and pVAX-LP-IRES-LUC plasmid only, respectively; as follows, \%: $72.37(\mathrm{P}<0.01), 74.56(\mathrm{P}<0.05)$ and 56.63 (NS) compared to cells transfected with pRdRp-full, pVAX-N-IRES-LUC and pVAX-LP-IRES-LUC plasmid, respectively, followed by transfection with siGFP. Of note, we found no significant difference in luciferase expression between cells transfected with plasmid only or after co-transfection with plasmid and non-specific siGFP (table 1, fig. 2). According to results plotted at figure 2 and listed in table 1, siN-3, siN-4, siR-7 and siR-11 significantly reduced luciferase expression in both cells treated with plasmid only and cells cotransfected with plasmid and siRNA. The latter molecules were chosen as the most potent SARS-CoV-2 silencing siRNAs and were further studied.

Antiviral effect of siRNA in vitro

Next, we investigated the antiviral effects of the four selected siRNAs (siN-3, siN-4, siR-7 and siR-11) in vitro . To evaluate their antiviral effect, we transfected Vero E6 cells with complexes of siRNA/Lipofectamine 3000 and four hours after transfection cells were infected with SARS-CoV-2 at MOI 0.0001. After 48 hours infection cells were lysed and viral RNA (vRNA) concentration was determined by qRT-PCR. We found 
a significant difference in vRNA concentration between cells treated with specific siR-7, compared to both unspecific siLuc-transfected and infected cells $(\mathrm{P}<0.05)$ (fig.2d). In addition, a significant reduction of vRNA in cells treated with siN-4 $(\mathrm{P}<0.05)$ compared to SARS-CoV-2 infected cells and a trend towards significance $(\mathrm{P}=0.0571)$ to reduce the amount of vRNA compared to unspecific siLuc-transfected cells were observed. According to these results the siR-7 targeting SARS-CoV-2 RdRp gene was chosen as best candidate for further analysis.

The peptide dendrimer KK-46 enhances transfection efficiency

A novel formulation KK-46 based on a peptide dendrimer was developed for safe and efficient nucleic acid delivery. In order to evaluate the transfection activity of KK-46 (Fig. 2e), Hep-2 cells were transfected with mixtures of pGL3 Luciferase Reporter Vectors (Promega)/ peptide dendrimer KK-46 at weight ratios of 5:1,12.5:1, 20:1, 25:1, 50:1, 100:1 (KK-46:pGL3). The commercial transfection reagent Lipofectamine 3000 was used as positive control. As shown in Figure 2e the weight ratios 20:1 and 25:1 yielded the highest levels of luciferase activity compared to ratio 5:1 $(\mathrm{P}<0.01)$ and for the 25:1 ratio it was even significantly higher than with commercial Lipofectamine $3000(\mathrm{P}<0.05)$. The half maximal inhibitory concentration $\left(\mathrm{IC}_{50}\right)$ of KK-46 measured by MTT test for Vero cells was $548 \pm 23 \mu \mathrm{g} / \mathrm{mL}$ (data not shown). Thus, the optimal concentration of KK46 at 20-25 $\mathrm{g} / \mathrm{mL}$ was much lower than $\mathrm{IC}_{50}$. A testing of KK46 regarding its ability to block the RBD-ACE2 interaction showed no inhibition up to $100 \mu \mathrm{g} / \mathrm{mL}$ (data not shown).

Modified siR-7-EM shows increased nuclease resistance

Introduction of LNA into classic antisense oligos has been shown to increase their stability(32). Therefore, we designed LNA-modified siR-7-EM to test if these modifications could improve the properties of siR-7 for in vivo application. Stability of unmodified siR-7 and LNA-modified siR-7-EM was evaluatedin vitro by incubation in $50 \%$ mouse serum for $264 \mathrm{~h}$ at $37^{\circ} \mathrm{C}$. As shown in Figure 3, unmodified siR-7 was markedly degraded after $48 \mathrm{~h}$ of incubation. In contrast, LNA-modified siR-7-EM did not show signs of degradation even after $264 \mathrm{~h}$ of incubation. Moreover, we found that the half-life $\left(\mathrm{t}_{1 / 2}\right)$ of siR-7 and siR-7-EM were 72.4 and 256.8 h, respectively (Fig. 3a). These experiments showed that incorporation of LNA molecules in siR-7 contributes to increased half-life and thus may have a positive influence on overall biostability.

siR-7-EM / peptide dendrimer KK-46 complexes exhibit strong anti-SARS-CoV-2 activity in vitro

To examine whether the LNA-modification may influence the knockout activity and to evaluate KK-46 transfection activity with siRNA Vero E6 cells were transfected with unmodified siR-7 or LNA- modified siR-7-EM/ KK-46 complexes and infected with SARS-CoV-2. Viral load in cells lysate and supernatants was determined by qRT-PCR $48 \mathrm{~h}$ after infection. Three increasing concentrations of complex $21,42 \mathrm{and} 84 \mu \mathrm{g} / \mathrm{per}$ well which included sum of siRNA/siLNA+KK-46, $\mu \mathrm{g}: 1+20,2+40$ and $4+80$ were used, respectively. As shown in Figure 4, up to a two-log reduction in vRNA levels in cell lysates (Fig.4a; $\mathrm{P}<0.01$ ) and supernatants (Fig. 4b; $\mathrm{P}<0.01, \mathrm{P}<0.05$ ), were achieved after $48 \mathrm{~h}$ using either 42 or $84 \mu \mathrm{g}$ of both siR-7 and siR-7-EM /KK46 complexes. Complexes containing unspecified siLuc (targeting gene of firefly luciferase) with SARS-CoV-2 infected cells were used as negative control showing no significant reduction of vRNA levels as compared to SARS-CoV-2-infected cells (Fig. 4). Significant reduction of vRNA in both cell lysate and supernatants compared to unspecific siLuc and infectious control was observed at a dose of $42 \mu \mathrm{g}(\mathrm{P}<0.01, \mathrm{P}<0.05)$. The target-specificity of the siR-7 or siR-7-EM /KK-46 complexes was reflected by the use of a untargeted siLuc control, which showed no significant off-target effects on the vRNA levels neither in cell lysates nor in supernatants. We found no significant difference in antiviral effects of unmodified siR-7 or LNA- modified siR-7-EM but complexes with siR-7-EM seemed to be more effective than siR-7 complexes which was also reflected by the fact that only the $21 \mu \mathrm{g}$ dose of siR-7-EM gave significant results compared to siLuc, $\mathrm{P}<0.05$.

\section{siR-7-EM / KK-46 complexes show strong anti-SARS-CoV-2 effectsin vivo}

In order to investigate the therapeutic potential of the siR-7-EM/KK-46 complex in vivo, female Syrian hamsters were infected with SARS-CoV-2 at dose of $10^{5} \mathrm{PFU} /$ animal and then given a single inhalation exposure of $0.7,1.96$ and $5.6 \mathrm{mg} / \mathrm{kg}$ of siR-7-EM/KK-46 per day for 6 days. This schedule was thought as 
an early topical post-exposure treatment. Half of the animals were sacrificed two and six days post infection, respectively. Viral loads were evaluated in the lungs by virus titration and expressed as plaque forming units (PFU) per $1 \mathrm{~mL}$. We found that progeny virus production was significantly and dose-dependently decreased. Up to a 1.5-3 times reduction, in the lungs of the siR-7-EM/KK-46-treated animals on day two $(5.0 \pm 0.5,4.7$ $\pm 0.2,4.5 \pm 0.3 \mathrm{in} \log 10 \mathrm{PFU} / \mathrm{mL}$ for $0.7,1.96$ and $5.6 \mathrm{mg} / \mathrm{kg}$ of siR-7-EM/KK-46, respectively), compared to infected and untreated animals was found $(6.1 \pm 0.2), \mathrm{P}<0.01$. (Fig. 5a). Similar results were obtained for the other half of animals which were analyzed on day six. Again, treatment with siR-7-EM/KK-46 significantly and dose-dependently decreased viral loads in the lungs $(2.2 \pm 0.2,2.0 \pm 0.2,1.1 \pm 0.1$ in $\log 10 \mathrm{PFU} / \mathrm{mL}$ for $0.7,1.96$ and $5.6 \mathrm{mg} / \mathrm{kg}$ of siR-7-EM/KK-46, respectively) as compared with the infected and untreated animals $(3.5 \pm 0.2),(\mathrm{P}<0.01)$. The estimated ED50 was $3.453 \mathrm{mg} / \mathrm{kg} /$ day (GraphPad Prism8, non-linear fit, $\mathrm{R}^{2}=0.88$; Fig. $\left.5 \mathrm{~b}\right)$.

We also observed a reduction of viral load for the control group treated with oral administration of Hydroxychloroquine which was in the range of the siR-7-EM/KK-46-treated animals on day 2 and on day 6. However, effects of treatment with siR-7-EM/KK-46 on lung pathology were strikingly different from those observed with Hydroxychloroquine (Fig. 5c). Histological analysis (Fig. 5c) revealed significantly (p $<0.05$ and $\mathrm{p}<0.01$, at day two and six, respectively) decreased lung inflammation as assessed by macroscopic indicators of disease in animals exposed to $0.7,1.96$ and $5.6 \mathrm{mg} / \mathrm{kg}$ of siR-7-EM/KK-46 as compared to SARS-CoV-2 infected, untreated animals group (Fig. 5c). By contrast, no significant improvement of lung pathology was found in the Hydroxychloroquine treated animals as compared to the infected and untreated animals (Fig. 5c). Taken together these results suggested that inhalation of siR-7-EM/KK-46 at a dose of $3.5 \mathrm{mg} / \mathrm{kg}$ significantly and dose-dependently attenuates pathological effects in vivo by hindering viral replication.

To further investigate alternative dosing schemes of siR-7-EM/KK-46, a multiple dose study with repeated low doses of siR-7-EM/KK-46 was conducted. In this second set of in vivo experiments Syrian hamsters were infected with SARS-CoV-2 and treated with $0.175,0.35$ and $1.0 \mathrm{mg} / \mathrm{kg}$ (yielding daily doses of $0.35,0.7$ and $2.0 \mathrm{mg} / \mathrm{kg}$, respectively) of siR-7-EM/KK-46 inhalation exposure twice a day with two hours interval for 6 days. Again, viral load was evaluated in the lungs by virus titration and expressed as plaque forming units (PFU) per $1 \mathrm{~mL}$. The SARS-CoV-2 viral titers were found to be significantly reduced by the siR-7EM/KK-46 compared to the untreated virus-infected animals $(\mathrm{P}<0.01$ for all dose levels) at days two and six (Fig. 6a). In particular, viral titers were reduced a $1.3(26)$ and $2.5(54)$ times (\%) on day two and six, respectively, in the lungs of the siR-7-EM/KK-46-treated animals on day two $(5.1+-0.1,4.9+-0.2$, 4.9 +- 0.1 in $\log 10 \mathrm{PFU} / \mathrm{mL}$ for $0.35,0.7$ and $2.0 \mathrm{mg} / \mathrm{kg}$, of siR-7-EM/ KK-46, respectively), compared with results for the untreated, virus-infected animals $(6.7+-0.03), \mathrm{P}<0.01$. Also, on day six viral titers in the siR-7-EM/KK-46-treated animals were significantly reduced $(1.7+-0.1,1.6+-0.2,1.3+-0.1$ in $\log 10$ $\mathrm{PFU} / \mathrm{mL}$ for $0.35,0.7$ and $2.0 \mathrm{mg} / \mathrm{kg}$ of siR-7-EM/KK-46, respectively) as compared with the untreated, virus-infected animals $(3.3+-0.1),(\mathrm{P}<0.01)$. Oral administration of Favipiravir reduced the viral titer approximately 1.2-times on day two (5.4+- 0.1) compared to SARS-CoV-2-infected and untreated animals $(\mathrm{P}<0.01)$.

Again, we performed scoring of lung pathology and found significantly $(\mathrm{P}<0.01)$ decreased lung inflammation in animals exposed to $2 \mathrm{mg} / \mathrm{kg}$ of siR-7-EM/KK-46 aerosol compared to SARS-CoV-2 infected group at day six but not in the animals treated with lower doses of siR-7-EM/KK-46 or with Favipiravir as compared to the infected but untreated animals. However, this significant reduction was only found after 6 days suggesting that the dose should be $2 \mathrm{mg} / \mathrm{kg}$ or higher.

\section{Discussion}

The novel human coronavirus disease, COVID-19, caused by SARS-CoV-2 has become the first coronavirus pandemic in history(33). Numerous clinical trials and ongoing research aimed to identify therapeutic strategies based on existing and repurposed as well as novel antiviral drugs for COVID-19(34). Furthermore, active vaccination and passive immunization with convalescent plasma and recombinant SARS-CoV-2-specific antibodies has reached clinical application. However, a huge unmet need for virus-specific treatment remains. 
Here we present data showing that topical application by inhalation of SARS-CoV-2-specific modified siRNA with enhanced stability formulated with a peptide dendrimer facilitating siRNA transfer into infected cells has the potential to treat SARS-CoV-2-induced lung inflammation using the Syrian hamster model. In fact, small interfering RNA-mediated gene silencing technology (siRNA) holds promise for drug development. Recently two RNA interference (RNAi)-based drugs GIVLAARI(r) for acute hepatic porphyria and ONPATTRO for the treatment of the polyneuropathy of hereditary transthyretin-mediated amyloidosis(35) were approved in both the European Union and the United States. Several anti-HBV, HCV, HIV, Zaire ebolavirus (ZEBOV) and RSV (respiratory syncytial virus) siRNA-based formulations have been evaluated in clinical trials(36). Furthermore, it has been shown that siRNAs could inhibit the replication of SARSCoV both in vitro(37-40) and in vivo $(41,42)$ and in silico exploration of potential siRNA targets in the SARS-CoV-2 genome has been reported(43).

Research in COVID-19 is rapidly expanding but to the best of our knowledge our study is the first which not only evaluated the antiviral efficiency of siRNAs targeting the SARS-CoV-2 genome but also sought to overcome possible bottlenecks of a therapeutic SARS-CoV-2 siRNA approach. Designing siRNAs with antiviral activity is a challenging task(44). First sequences of siRNAs must be identified which are highly specific minimizing potential off-target effects and are highly effective in silencing. Second, effective and safe forms of delivery must be developed to introduce the siRNAs into infected cells. Finally, it is important to prevent degradation of siRNAs by nucleases and to avoid unwanted inflammation/immunostimulation.

In order to identify SARS-CoV-2-specific siRNAs which are highly effective in silencing siRNA sequences targeting ORF1a (leader protein), $\mathrm{N}$ and RdRP genes of SARS-CoV-2 were designed in silico (27) and tested in vitro to choose the siRNAs which are most powerful in silencing. In order to reduce working with infectious virus the first screening of potential antiviral siRNAs was performed using plasmids containing SARS-CoV-2 genes fused with the firefly luciferase gene, which allows estimating the silencing potency of the siRNAs by assessing the redaction of the luciferase activity in the treated cells. Specific siRNAs targeting the gene of firefly luciferase and GFP were used as positive and negative control, respectively. According to this screening assay 4 out of 15 tested siRNAs (siN-3, siN-4, siR-7 and siR-11) targeting SARS-CoV-2 genes $\mathrm{N}$ and RdRp, respectively, were found to be most effective. The specificity of the screening assay was demonstrated by the fact that siGFP (negative control had no effects). Next, we evaluated the specific antiviral activity of the chosen siRNA molecules in vitro using Vero E6 cells infected with SARS-CoV-2. These experiments identified siR-7 as best molecule because it significantly decreases the number of viral RNA (vRNA) in infected cells as compared to cells only infected with SARS-CoV-2 as well as in infected cells which had been transfected with a SARS-CoV-2-unrelated siRNA (i.e., siLuc) (Fig. 2d). These results are important because they showed that siR-7 targeting of the RdRp gene was specific and not due to a non-specific effect of the transfection of cells with siRNA per se. In initial experiments using cultivated virusinfected cells, commercial Lipofectamine 3000 was used as vehicle for siRNA. However, it is not recommended for in vivo use. Although it has been reported that local delivery of unmodified naked siRNA to the lung can be successful(45)'(46)'(47) we decided to further modify siR-7 to enhance its entrance into cells, to render it resistant to nuclease and to decrease off-target effects. Therefore, we designed a novel formulation KK-46 based on peptide dendrimers (PD) to achieve safe and efficient siRNA delivery into the lung. Dendrimers are branched three-dimensional structures containing a central core surrounded by peripheral positively charged groups which promote their binding and condensation to nucleic acid molecules(48). PDs contains mostly unnatural $\varepsilon$-amide bonds on lysine residues, which increase resistance against proteolytic digestion $(49,50)$. Moreover, PDs are less toxic than linear peptides comprising the same combinations of amino acids (51). Several types of dendrimers have been explored for siRNA delivery and gave promising results(52). Based on our previous results(50) and in silicocalculation of the molecular properties for achieving positive charge and amphiphilicity for cell penetration and RNA-binding we designed the cationic PD KK-46. The positive charge was attributable to the use of arginine and histidine residues for the N-terminal ends of the peptide branches. A dendrimeric lysine core and hydrophobic amino acid residues contributed to the increase of amphiphilicity of the peptide. To determine the optimal concentration for in vivo use of KK-46 we transfected Hep-2 cells with pGL3 Luciferase Reporter Vectors /KK-46 complexes at different concentrations and found that the 
optimal concentration of KK46 at $20-25 \mu \mathrm{g} / \mathrm{mL}$ for transfection was significantly lower than its $\mathrm{IC}_{50}=548 \pm 23$ $\mu \mathrm{g} / \mathrm{mL}$ as evaluated by MTT testing of Vero cells. As DNA and RNA possess a similar structure in terms of nucleic acid framework and their electronegative nature(52), we calculated a 20:1 ratio of KK-46:siRNA for further experiments.

In addition to identifying KK-46 as a possible pharmacologically acceptable vehicle for in vivo use we also tried to optimize the siR-7 molecule itself. It has been shown that potential off-target effects and unwanted immunostimulatory effects of siRNAs as well as their biodegradation may be reduced by incorporation of Locked nucleic acids (LNAs) in the siRNA sequence. LNA nucleotides contain a methylene linkage connecting the 2' oxygen and 4' carbon of the ribose ring that leads to a reduction of the conformational flexibility of the ribose(53). siRNA molecules have the potential to induce inflammatory response by effects on the innate immune system through activation of Toll-like receptors(54). LNA incorporation has been shown to inhibit such immune stimulation. In particular, LNA modification at the 3' end of the siRNA passenger strand, strongly inhibited IFN $\alpha$ induction without affecting knockout activity(55). Moreover LNA-incorporation can increase endo- and exonuclease resistance and sequence-related off-target effects(56). We therefore incorporated LNA-modification to the 3' ends of siR-7 guide and passenger strands to improve it stability and functionality and found that this significantly increases the half-life compared to unmodified siRNA (Fig.3). Next, we investigated whether the LNA-modification may have a negative influence on the knockout efficacy. For this purpose, we transfected Vero E6 cells with unmodified siR-7 or LNA-modified siR-7$\mathrm{EM} /$ peptide dendrimer complex at three increasing concentrations of siRNA/siLNA and KK-46 (Fig. 4F). We found that LNA-modification did not affect specific virus gene silencing which is in accordance with a previous study (56). We thus could establish a formulation of LNA-modified siR-7-EM targeted to RdRp gene of SARS-CoV-2 in complex with the KK-46 peptide dendrimer which revealed strong and specific antiviral activity in vitro .

Topically applied siRNAs have been shown to be highly effective for inhibition of herpes simplex virus (HSV) and RSV in animal models $(57,58)$. We therefore envisaged topical treatment in the lung by inhalation for the treatment of COVID-19. Furthermore, the lung is a major target for the disease due to high expression of ACE2 and long-term lung damage is a major complication of COVID-19(59). Moreover, nebulizers or inhalers are available to generate aerosols for drug delivery by inhalation(60).

For the in vivo studies we used the model based on Syrian hamsters which has been shown to be a suitable small animal model for COVID-19(61) and was also used to evaluate the effects of vaccination and passive immunization strategies with monoclonal antibodies $(14,62)$ which afterwards also showed promising results in clinical trials. Due to the fact that the half-life of siR-7-EM/KK-46 after inhalation was only short (i.e., $23 \mathrm{~min}$ ) we performed daily treatment of SARS-CoV-2-infected animal with two applications of different doses of siR-7-EM/KK-46 (0.7, 1.96 or $5.6 \mathrm{mg} / \mathrm{kg}$ daily) and evaluated the effects after two and six days. We found a dose-dependent effect of treatment in terms of a significant reduction of viral load and most importantly, reduced lung inflammation on days 2 and day 6 as compared to non-treated infected animals. In addition, we conducted additional studies evaluating lower doses which confirmed that treatment by daily twice inhalation of siR-7-EM/KK-46 reduced viral load and lung inflammation. Collectively the in vivo experiments indicated $3.453 \mathrm{mg} / \mathrm{kg}$ /day as the optimal dose for treatment in the Syrian Hamster model. The effect of treatment siR-7-EM/KK-46 may be estimated by comparing our results with those obtained by passive immunization with the monoclonal SARS-CoV-2-specific antibodies REGN10987 and REGN10933 which were used in a prophylactic and treatment setting in the Syrian Hamster model(14). In the latter study prophylactic treatment reduced viral load, albeit not in a significant manner, and significantly reduced lung inflammation as we observed for early therapeutic application of siR-7-EM/KK-46. The REGN cocktail of SARS-CoV-2 antibodies, which has demonstrated similar effects as siR-7-EM/KK-46 in the Syrian Hamster model, could also reduce viral load in a clinical trial performed in COVID-19 patients(15) and encourages us to further evaluate topical treatment by inhalation of siR-7-EM/KK-46 in COVID-19 patients to further explore the clinical utility of silencing SARS-CoV-2 by siRNA technology for specific treatment of COVID-19.

In fact, preclinical evaluation of siR-7-EM/KK-46 medication is now finished and a permission for clinical 
trial has been received from Ministry of Health of Russian Federation.

\section{Author Contributions}

All authors contributed to the writing of the manuscript and have approved the final version for publication. Conceptualization, Methodology: Khaitov M., Valenta R., Nikonova A., Shilovskiy I., Kofiadi I., Kozhikhova K., Smirnov V., Koloskova O., Andreev S., Martynov A., Berzin I., Khaitov R., Skvortsova V.; Investigation: Vishnyakova L., Nikolsky A., Kovchina V., Barvinskaya E., Yumashev K., Maerle A., Kozlov I., Shatilov A., Timofeeva A., Sergeev I., Trofimov D., Gushchin V., Kovalchuk A., Borisevich S., P. Gattinger; Formal analysis: Nikonova A., Shilovskiy I.; Writing - Original Draft: Khaitov M, Nikonova A.

\section{Competing Interests statement}

Rudolf Valenta has received research grants from the Austrian Science Fund (FWF), HVD Biotech, Vienna, Austria, Worg Pharmaceuticals, Hangzhou, China and Viravaxx, Vienna, Austria and serves as a consultant for Viravaxx. The other authors do not have any conflicts of interest.

References

1. Zhang JJ, Dong X, Cao YY, Yuan YD, Yang YB, Yan YQ, et al. Clinical characteristics of 140 patients infected with SARS-CoV-2 in Wuhan, China. Allergy2020;75 (7):1730-1741.

2. Azkur AK, Akdis M, Azkur D, Sokolowska M, van de Veen W, Bruggen MC, et al. Immune response to SARS-CoV-2 and mechanisms of immunopathological changes in COVID-19.Allergy 2020;75 (7):1564-1581.

3. Tang D, Comish P, Kang R. The hallmarks of COVID-19 disease. PLoS Pathog2020;16 (5):e1008536.

4. Morens DM, Folkers GK, Fauci AS. Emerging infections: a perpetual challenge. Lancet Infect Dis2008;8 (11):710-719.

5. Morens DM, Breman JG, Calisher CH, Doherty PC, Hahn BH, Keusch GT, et al. The Origin of COVID-19 and Why It Matters. Am J Trop Med Hyg 2020;103 (3):955-959.

6. Ramasamy MN, Minassian AM, Ewer KJ, Flaxman AL, Folegatti PM, Owens DR, et al. Safety and immunogenicity of $\mathrm{ChAdOx} 1 \mathrm{nCoV}-19$ vaccine administered in a prime-boost regimen in young and old adults (COV002): a single-blind, randomised, controlled, phase 2/3 trial. Lancet 2021;396 (10267):19791993.

7. Logunov DY, Dolzhikova IV, Zubkova OV, Tukhvatullin AI, Shcheblyakov DV, Dzharullaeva AS, et al. Safety and immunogenicity of an rAd26 and rAd5 vector-based heterologous prime-boost COVID-19 vaccine in two formulations: two open, non-randomised phase 1/2 studies from Russia. Lancet2020;396 (10255):887-897.

8. Mulligan MJ, Lyke KE, Kitchin N, Absalon J, Gurtman A, Lockhart S, et al. Phase I/II study of COVID-19 RNA vaccine BNT162b1 in adults. Nature2020;586 (7830):589-593.

9. Krammer F. SARS-CoV-2 vaccines in development. Nature 2020;586 (7830):516-527.

10. Pan H, Peto R, Henao-Restrepo AM, Preziosi MP, Sathiyamoorthy V, Abdool Karim Q, et al. Repurposed Antiviral Drugs for Covid-19 - Interim WHO Solidarity Trial Results. N Engl J Med 2020.

11. Beigel JH, Tomashek KM, Dodd LE, Mehta AK, Zingman BS, Kalil AC, et al. Remdesivir for the Treatment of Covid-19 - Final Report. N Engl J Med2020;383 (19):1813-1826.

12. Liu STH, Lin HM, Baine I, Wajnberg A, Gumprecht JP, Rahman F, et al. Convalescent plasma treatment of severe COVID-19: a propensity score-matched control study. Nat Med 2020;26 (11):1708-1713.

13. Tanne JH. Covid-19: FDA approves use of convalescent plasma to treat critically ill patients. BMJ2020;368:m1256. 
14. Baum A, Ajithdoss D, Copin R, Zhou A, Lanza K, Negron N, et al. REGN-COV2 antibodies prevent and treat SARS-CoV-2 infection in rhesus macaques and hamsters. Science2020;370 (6520):1110-1115.

15. Weinreich DM, Sivapalasingam S, Norton T, Ali S, Gao H, Bhore R, et al. REGN-COV2, a Neutralizing Antibody Cocktail, in Outpatients with Covid-19. N Engl J Med2020.

16. Harrison AG, Lin T, Wang P. Mechanisms of SARS-CoV-2 Transmission and Pathogenesis. Trends Immunol 2020;41 (12):1100-1115.

17. Thi Nhu Thao T, Labroussaa F, Ebert N, V'Kovski P, Stalder H, Portmann J, et al. Rapid reconstruction of SARS-CoV-2 using a synthetic genomics platform. Nature2020;582 (7813):561-565.

18. V'Kovski P, Kratzel A, Steiner S, Stalder H, Thiel V. Coronavirus biology and replication: implications for SARS-CoV-2. Nat Rev Microbiol 2020.

19. McManus MT, Sharp PA. Gene silencing in mammals by small interfering RNAs. Nat Rev Genet2002;3 (10):737-747.

20. Qin XF, An DS, Chen IS, Baltimore D. Inhibiting HIV-1 infection in human T cells by lentiviral-mediated delivery of small interfering RNA against CCR5. Proc Natl Acad Sci U S A 2003;100 (1):183-188.

21. Carmichael GG. Medicine: silencing viruses with RNA. Nature2002;418 (6896):379-380.

22. Jacque JM, Triques K, Stevenson M. Modulation of HIV-1 replication by RNA interference. Nature 2002;418 (6896):435-438.

23. Ahlquist P. RNA-dependent RNA polymerases, viruses, and RNA silencing. Science2002;296 (5571):1270-1273.

24. Fire A, Xu S, Montgomery MK, Kostas SA, Driver SE, Mello CC. Potent and specific genetic interference by double-stranded RNA in Caenorhabditis elegans. Nature1998;391 (6669):806-811.

25. Agrawal N, Dasaradhi PV, Mohmmed A, Malhotra P, Bhatnagar RK, Mukherjee SK. RNA interference: biology, mechanism, and applications. Microbiol Mol Biol Rev2003;67 (4):657-685.

26. Imai M, Iwatsuki-Horimoto K, Hatta M, Loeber S, Halfmann PJ, Nakajima N, et al. Syrian hamsters as a small animal model for SARS-CoV-2 infection and countermeasure development. Proc Natl Acad Sci U $S$ A2020;117 (28):16587-16595.

27. Khaitov M. R. Shilovskiy I.P., Kofiadi I. A., Sergeev I. V., Kozlov I. B., Smirnov V. V., Kozhikhova K. V., Koloskova O. O., Andreev S. M., Zhernov Y. V., Nikonova A.A., Inventor The siRNA-based drug for inhibition of the SARS-CoV-2 replication. Russia. 2020.

28. Faizuloev E, Marova A, Nikonova A, Volkova I, Gorshkova M, Izumrudov V. Water-soluble N-[(2-hydroxy3 -trimethylammonium)propyl]chitosan chloride as a nucleic acids vector for cell transfection. Carbohydr Polym2012;89 (4):1088-1094.

29. Khaitov M. R. Kozhikhova K.V., Koloskova O. O., Andreev S. M., Timofeeva A. V., Shatilov A. A., Shilovskiy I.P., Kofiadi I. A., Smirnov V. V., Nikonova A.A., Inventor The peptides for intracellular delivery of nucleic acids. Russia. 2020.

30. Gattinger P, Borochova K, Dorofeeva Y, Henning R, Kiss R, Kratzer B, et al. Antibodies in serum of convalescent patients following mild COVID-19 do not always prevent virus-receptor binding. Allergy 2020.

31. Borisevich S. V. Syromyatnikova S.I., Khamitov R. A., Markov V.I., Maximov V.A., Pistsov M. N., Inventor Composition of agar coating for titration of coronavirus-the causative agent of severe acute respiratory syndrome by plaque forming units Russia. 2008

32. Mook OR, Baas F, de Wissel MB, Fluiter K. Evaluation of locked nucleic acid-modified small interfering RNA in vitro and in vivo. Mol Cancer Ther2007;6 (3):833-843. 
33. Liu YC, Kuo RL, Shih SR. COVID-19: The first documented coronavirus pandemic in history. Biomed $J$ 2020;43 (4):328-333.

34. Jomah S, Asdaq SMB, Al-Yamani MJ. Clinical efficacy of antivirals against novel coronavirus (COVID19): A review. J Infect Public Health 2020;13 (9):1187-1195.

35. Hu B, Weng Y, Xia XH, Liang XJ, Huang Y. Clinical advances of siRNA therapeutics. J Gene Med2019;21 (7):e3097.

36. Levanova A, Poranen MM. RNA Interference as a Prospective Tool for the Control of Human Viral Infections. Front Microbiol 2018;9 :2151.

37. Li T, Zhang Y, Fu L, Yu C, Li X, Li Y, et al. siRNA targeting the leader sequence of SARS-CoV inhibits virus replication. Gene Ther 2005;12 (9):751-761.

38. Lu A, Zhang H, Zhang X, Wang H, Hu Q, Shen L, et al. Attenuation of SARS coronavirus by a short hairpin RNA expression plasmid targeting RNA-dependent RNA polymerase. Virology 2004;324 (1):84-89.

39. Zhang Y, Li T, Fu L, Yu C, Li Y, Xu X, et al. Silencing SARS-CoV Spike protein expression in cultured cells by RNA interference. FEBS Lett2004;560 (1-3):141-146.

40. He ML, Zheng B, Peng Y, Peiris JS, Poon LL, Yuen KY, et al. Inhibition of SARS-associated coronavirus infection and replication by RNA interference. JAMA2003;290 (20):2665-2666.

41. Tang Q, Li B, Woodle M, Lu PY. Application of siRNA against SARS in the rhesus macaque model. Methods Mol Biol 2008;442:139-158.

42. Li BJ, Tang Q, Cheng D, Qin C, Xie FY, Wei Q, et al. Using siRNA in prophylactic and therapeutic regimens against SARS coronavirus in Rhesus macaque. Nat Med2005;11 (9):944-951.

43. Chen W, Feng P, Liu K, Wu M, Lin H. Computational Identification of Small Interfering RNA Targets in SARS-CoV-2. Virol Sin 2020;35 (3):359-361.

44. Rothe D, Wade EJ, Kurreck J. Design of small interfering RNAs for antiviral applications. Methods Mol Biol 2011;721 :267-292.

45. Lam JK, Liang W, Chan HK. Pulmonary delivery of therapeutic siRNA. Adv Drug Deliv Rev2012;64 (1):1-15.

46. Khaitov MR, Shilovskiy IP, Nikonova AA, Shershakova NN, Kamyshnikov OY, Babakhin AA, et al. Small interfering RNAs targeted to interleukin- 4 and respiratory syncytial virus reduce airway inflammation in a mouse model of virus-induced asthma exacerbation. Hum Gene Ther 2014;25 (7):642-650.

47. Nikonova A, Shilovskiy I, Galitskaya M, Sokolova A, Sundukova M, Dmitrieva-Posocco O, et al. Respiratory syncytial virus upregulates IL-33 expression in mouse model of virus-induced inflammation exacerbation in OVA-sensitized mice and in asthmatic subjects. Cytokine 2020:155349.

48. Santos A, Veiga F, Figueiras A. Dendrimers as Pharmaceutical Excipients: Synthesis, Properties, Toxicity and Biomedical Applications. Materials (Basel)2019;13 (1).

49. Luo K, Li C, Wang G, Nie Y, He B, Wu Y, et al. Peptide dendrimers as efficient and biocompatible gene delivery vectors: Synthesis and in vitro characterization. J Control Release 2011;155 (1):77-87.

50. Kozhikhova KV, Andreev SM, Shilovskiy IP, Timofeeva AV, Gaisina AR, Shatilov AA, et al. A novel peptide dendrimer LTP efficiently facilitates transfection of mammalian cells. Org Biomol Chem 2018;16 (43):8181-8190.

51. Eggimann GA, Blattes E, Buschor S, Biswas R, Kammer SM, Darbre T, et al. Designed cell penetrating peptide dendrimers efficiently internalize cargo into cells. Chem Commun (Camb) 2014;50 (55):7254-7257. 
52. Wu J, Huang W, He Z. Dendrimers as carriers for siRNA delivery and gene silencing: a review.Scientific WorldJournal 2013;2013:630654.

53. Braasch DA, Corey DR. Locked nucleic acid (LNA): fine-tuning the recognition of DNA and RNA.Chem Biol 2001;8 (1):1-7.

54. Meng Z, Lu M. RNA Interference-Induced Innate Immunity, Off-Target Effect, or Immune Adjuvant? Front Immunol 2017;8 :331.

55. Jackson AL, Linsley PS. Recognizing and avoiding siRNA off-target effects for target identification and therapeutic application. Nat Rev Drug Discov2010;9 (1):57-67.

56. Elmen J, Thonberg H, Ljungberg K, Frieden M, Westergaard M, Xu Y, et al. Locked nucleic acid (LNA) mediated improvements in siRNA stability and functionality. Nucleic Acids Res 2005;33 (1):439-447.

57. Paavilainen H, Lehtinen J, Romanovskaya A, Nygardas M, Bamford DH, Poranen MM, et al. Topical treatment of herpes simplex virus infection with enzymatically created siRNA swarm. Antivir Ther 2017;22 (7):631-637.

58. Bitko V, Musiyenko A, Shulyayeva O, Barik S. Inhibition of respiratory viruses by nasally administered siRNA. Nat Med 2005;11 (1):50-55.

59. Zou X, Chen K, Zou J, Han P, Hao J, Han Z. Single-cell RNA-seq data analysis on the receptor ACE2 expression reveals the potential risk of different human organs vulnerable to $2019-\mathrm{nCoV}$ infection. Front Med2020;14 (2):185-192.

60. Youngren-Ortiz SR, Gandhi NS, Espana-Serrano L, Chougule MB. Aerosol Delivery of siRNA to the Lungs. Part 1: Rationale for Gene Delivery Systems. Kona2016;33 :63-85.

61. Munoz-Fontela C, Dowling WE, Funnell SGP, Gsell PS, Riveros-Balta AX, Albrecht RA, et al. Animal models for COVID-19. Nature 2020;586 (7830):509-515.

62. Tostanoski LH, Wegmann F, Martinot AJ, Loos C, McMahan K, Mercado NB, et al. Ad26 vaccine protects against SARS-CoV-2 severe clinical disease in hamsters. Nat Med2020;26 (11):1694-1700.

Table 1. The suppression of luciferase activity by siRNA in Hep-2 cells consecutively transfected with plasmid coding SARS-CoV-2 genes fused with firefly luciferase gene and specific or nonspecific siRNAs.

\begin{tabular}{|c|c|c|c|c|}
\hline & siRNA name & $\begin{array}{l}\text { The suppression } \\
\text { of luciferase } \\
\text { activity (\%, } \\
\mathrm{N}=5) \text { in } \\
\text { comparison with: }\end{array}$ & $\begin{array}{l}\text { The suppression } \\
\text { of luciferase } \\
\text { activity (\%, } \\
\mathrm{N}=5 \text { ) in } \\
\text { comparison with: }\end{array}$ & $\begin{array}{l}\text { The suppression } \\
\text { of luciferase } \\
\text { activity (\%, } \\
\mathrm{N}=5 \text { ) in } \\
\text { comparison with: }\end{array}$ \\
\hline & & plasmid & plasmid & nonspecific siGFP \\
\hline 1 & siLuc & pRdRp-full & 70.24 & 72.37 \\
\hline $1 \mathbf{a}$ & siLuc & $\begin{array}{l}\text { pVAX-N-IRES- } \\
\text { LUC }\end{array}$ & 77.69 & 74.56 \\
\hline $1 b$ & siLuc & $\begin{array}{l}\text { pVAX-LP-IRES- } \\
\text { LUC }\end{array}$ & 53.1 & 56.63 \\
\hline 2 & siLP-1 & $\begin{array}{l}\text { pVAX-LP-IRES- } \\
\text { LUC }\end{array}$ & 83.43 & 84.67 \\
\hline 3 & siN-2 & $\begin{array}{l}\text { pVAX-N-IRES- } \\
\text { LUC }\end{array}$ & 49.61 & 42.53 \\
\hline 4 & siN-3 & $\begin{array}{l}\text { pVAX-N-IRES- } \\
\text { LUC }\end{array}$ & 69.21 & 64.88 \\
\hline 5 & $\operatorname{siN}-4$ & $\begin{array}{l}\text { pVAX-N-IRES- } \\
\text { LUC }\end{array}$ & 84.03 & 81.78 \\
\hline
\end{tabular}




\begin{tabular}{|c|c|c|c|c|}
\hline & siRNA name & $\begin{array}{l}\text { The suppression } \\
\text { of luciferase } \\
\text { activity (\%, } \\
\mathrm{N}=5) \text { in } \\
\text { comparison with: }\end{array}$ & $\begin{array}{l}\text { The suppression } \\
\text { of luciferase } \\
\text { activity (\%, } \\
\mathrm{N}=5 \text { ) in } \\
\text { comparison with: }\end{array}$ & $\begin{array}{l}\text { The suppression } \\
\text { of luciferase } \\
\text { activity (\%, } \\
\mathrm{N}=5) \text { in } \\
\text { comparison with: }\end{array}$ \\
\hline 6 & siN-5 & $\begin{array}{l}\text { pVAX-N-IRES- } \\
\text { LUC }\end{array}$ & 67.95 & 63.45 \\
\hline 7 & siR-6 & pRdRp-full & 74.53 & 76.35 \\
\hline 8 & siR-7 & pRdRp-full & 88.28 & 89.12 \\
\hline 9 & siR-8 & pRdRp-full & 41.74 & 45.91 \\
\hline 10 & siR-9 & pRdRp-full & 45.81 & 49.68 \\
\hline 11 & siR-10 & pRdRp-full & 54.16 & 57.44 \\
\hline 12 & siR-11 & pRdRp-full & 68.77 & 71 \\
\hline 13 & siR-12 & pRdRp-full & 37.26 & 41.74 \\
\hline 14 & siR-13 & pRdRp-full & 65.17 & 67.66 \\
\hline 15 & siR-14 & pRdRp-full & 26.81 & 32.04 \\
\hline 16 & siR-15 & pRdRp-full & 60.73 & 63.52 \\
\hline
\end{tabular}

Figure legends.

Figure 1. Plasmid constructs and design of siRNAs

Schematic representation of the bicistronic expression plasmid coding genes of firefly luciferase (Luc) and full size RdRp (pRdRp-full) (a) Nsp1 (pVAX-LP-IRES-LUC) (b), or N (pVAX-N-IRES-LUC) (c) genes of SARS-CoV-2.

(d) Positions of the siRNA targeting SARS-CoV-2 LP (siLP-1), RdRp (siR-6-siR-15) and N (siN-2-siN-5) genes. The RT-PCR-amplified region at the most upstream region of ORF1 (NSP1- leader protein) is marked.

Figure 2. Property of designed siRNA and peptide dendrimer KK-46

(a-c) Inhibition of gene expression with synthetic siRNA.

Hep-2 cells were transfected with each of the plasmids coding SARS-CoV-2 genes fused with firefly luciferase gene (pRdRp-full) (a), pVAX-N-IRES-LUC (b) or pVAX-LP-IRES-LUC (c) followed by transfection with SARS-CoV-2-specific or control siRNA. siLuc and siGFP were used as positive and negative controls, respectively. LipofectamineTM 3000 was used as vehicle for both pDNA and siRNA. After $24 \mathrm{~h}$ cells were harvested and luciferase activity was determined. Data are expressed as relative light units (RLU) per 104 cells.

Footnotes: $* /+$ or adjusted $\mathrm{p}$ value above/below represents the difference compared to cells transfected with plasmid only/non-specific siGFP, respectively. ${ }^{*}+\mathrm{P}<0.05,{ }^{* *}++\mathrm{P}<0.01,{ }^{* * *} \mathrm{P}<0.001$.

(d) Inhibition of SARS-CoV-2 reproduction with synthetic siRNA.

Vero E6 cells were transfected with siRNA/ LipofectamineTM 3000 complexes. Media with complexes were removed four hours after transfection and cells were infected with SARS-CoV-2 at MOI 0.0001. Viral load was determined by qRT-PCR. The results are expressed as viral RNA copies per mL.

Footnotes: ${ }^{*}$ or $\mathrm{p}=0.571$ represent differences with cells infected with SARS-CoV-2 and treated with nonspecific siLuc. + represent differences with SARS-CoV-2 only infected cells. ${ }^{*}+\mathrm{P}<0.05$.

(e) Gene delivery properties of the peptide dendrimer KK-46 
Hep-2 cells were transfected with complexes of pGL3 Luciferase Reporter Vectors $(0.25 \mu \mathrm{g})$ and different amounts of peptide dendrimer KK-46 (x-axis) at different ratios 100:1, 50:1, 25:1, 20:1,12.5:1,5:1. Luciferase activity was evaluated. The pGL3/Lipofectamine 3000 complex was used as positive controls. Data are expressed as relative light units (RLU) per 104 cells.

For a-d differences between multiple groups were estimated using a Kruskal-Wallis test followed by post-hoc testing (if the Kruskal-Wallis was significant) using un-paired Mann-Whitney U tests. Bars show medians of five independent experiments+ SDs.

For e differences between multiple groups were analyzed using one-way analysis of variance (ANOVA) with Tukey's post hoc test. Bars show medians of five independent experiments+ SEM. ${ }^{*} \mathrm{P}<0.05,{ }^{* *} \mathrm{P}<0.01$.

Figure 3. Modified siRNA have increased resistance to nuclease degradation. (a) The stability of unmodified siR-7 (circles) and modified siR-7-EM (squares) in 50\% mouse serum are compared over a period of $264 \mathrm{~h}$ at $37^{\circ} \mathrm{C}(\mathrm{N}=4)$. siRNA quantities at various time points were calculated by dividing the total counts of full-length siRNA by the input starting material. (b) For this purpose, aliquots of each sample (10ug siRNA per lane) were analyzed by $1.5 \%$ agarose gel electrophoresis. Differences between multiple groups were analyzed using repeated measures one-way ANOVA with Dunnetts's post hoc test. Bars show medians of four independent experiments+SEM. ${ }^{* * * *} \mathrm{P}<0.0001$.

Figure 4. Inhibition of SARS-CoV-2 reproduction with unmodified or LNA-modified siR-7/ peptide dendrimer KK-46 complexes in vitro.

Vero E6 cells were transfected with unmodified siR-7 or LNA-modified siR-7-EM-peptide dendrimer KK-46 complexes at three concentrations (x-axes). Media with complexes were removed four hours after transfection and cells were infected with SARS-CoV-2 at MOI 0.0001. After 48 hours supernatants and cells were harvested. Viral load was determined by qRT-PCR in cells lysates (a) and supernatants (b). The results are expressed as viral RNA copies per mL. Differences between multiple groups were estimated using a Kruskal-Wallis test followed by post-hoc testing (if the Kruskal-Wallis was significant) using un-paired Mann-Whitney U tests. Bars show medians of five independent experiments + SDs.

Footnotes: \# represent differences with cells infected with SARS-CoV-2 and treated with non-specific siLuc. ${ }^{*}$ represent differences with SARS-CoV-2 only infected cells. ${ }^{*} \# \mathrm{P}<0.05,{ }^{*} \# \# \mathrm{P}<0.01$.

Figure 5. Dose-dependent inhibition of SARS-CoV-2 reproduction with modified siR-7-EM-peptide dendrimer KK-46 complexes in Syrian hamsters after repeated inhalation exposure.

Syrian hamsters were infected with SARS-CoV-2 with a dose of $105 \mathrm{PFU} /$ animal and treated with three doses of the modified siR-7-EM-peptide dendrimer KK-46 complexes (35, 98 and $289 \mu \mathrm{g}$ siR-7-EM/animal, $0.7,1.96$ and $5.6 \mathrm{mg} \mathrm{KK}-46 / \mathrm{kg}$, respectively). Inhalations with complexes were repeated daily for six days. Two and six days after infection animals were sacrificed and determination of viral titer (a) and macroscopic evaluation plus scoring of histopathology (b) in the lung were performed. Orally administrated Hydroxychloroquine (within 1 hour after infection, a dose of $3.8 \mathrm{mg} /$ animal and then daily for 6 days post infection $1.5 \mathrm{mg} /$ animal) served as control. The results are expressed as plaque forming units (PFU) per $\mathrm{mL}$ (a) or scores (b) obtained for histological analysis of pathologic alterations in hamsters' lung. (c) Doseresponse curve of SARS-CoV-2 levels in the lungs at day six after infection, where the ED50 estimation is $3.453 \mathrm{mg} / \mathrm{kg}$.

Differences between multiple groups were estimated using a Kruskal-Wallis test followed by post-hoc testing (if the Kruskal-Wallis was significant) using un-paired Mann-Whitney U tests. Bars show medians of one experiment (five animals per group) + SDs. Data are provided for one experiment representative of two independent experiments with five hamsters /group.

Footnotes: */+ represent differences with hamsters infected with SARS-CoV-2 and assessed at day two/ six 
after infection, respectively. $* *++\mathrm{P}<0.01,{ }^{*} \mathrm{P}<0.05$.

Figure 6. Effect of repeated low dose modified siR-7-EM-peptide dendrimer KK-46 complexes in Syrian hamsters.

Syrian hamsters were infected with SARS-CoV-2 at a dose of $105 \mathrm{PFU} /$ animal and exposed to different doses $(0.175,0.35$ and $1.0 \mathrm{mg} / \mathrm{kg}$ of siR-7-EM/KK-46 aerosol) twice a day with two hours interval. Two and six days after infection animals were sacrificed and viral titers (a) and macroscopic evaluation and scoring of the histopathology lesions (b) in the lung were analyzed. Orally administrated Favipiravir (1 hour after infection, a dose of $1.2 \mathrm{mg}$ /animal was administered twice a day, and then daily during 6 days after infection $0.4 \mathrm{mg} /$ animal twice a day) served as positive control. The results are expressed as plaque forming units (PFU) per $\mathrm{mL}(\mathrm{a})$ or scores (b) obtained for histological analysis of pathologic lung alterations.

Differences between multiple groups were estimated using a Kruskal-Wallis test followed by post-hoc testing (if the Kruskal-Wallis was significant) using un-paired Mann-Whitney U tests. Bars show medians of one experiment (five animals per group) + SDs. Data are from one experiment representative of two independent experiments with five hamsters /group are shown.

Footnotes: $* /+$ represents difference with hamsters infected with SARS-CoV-2 and assessed at day two/ six after infection, respectively. ${ }^{* *}++\mathrm{P}<0.01$.
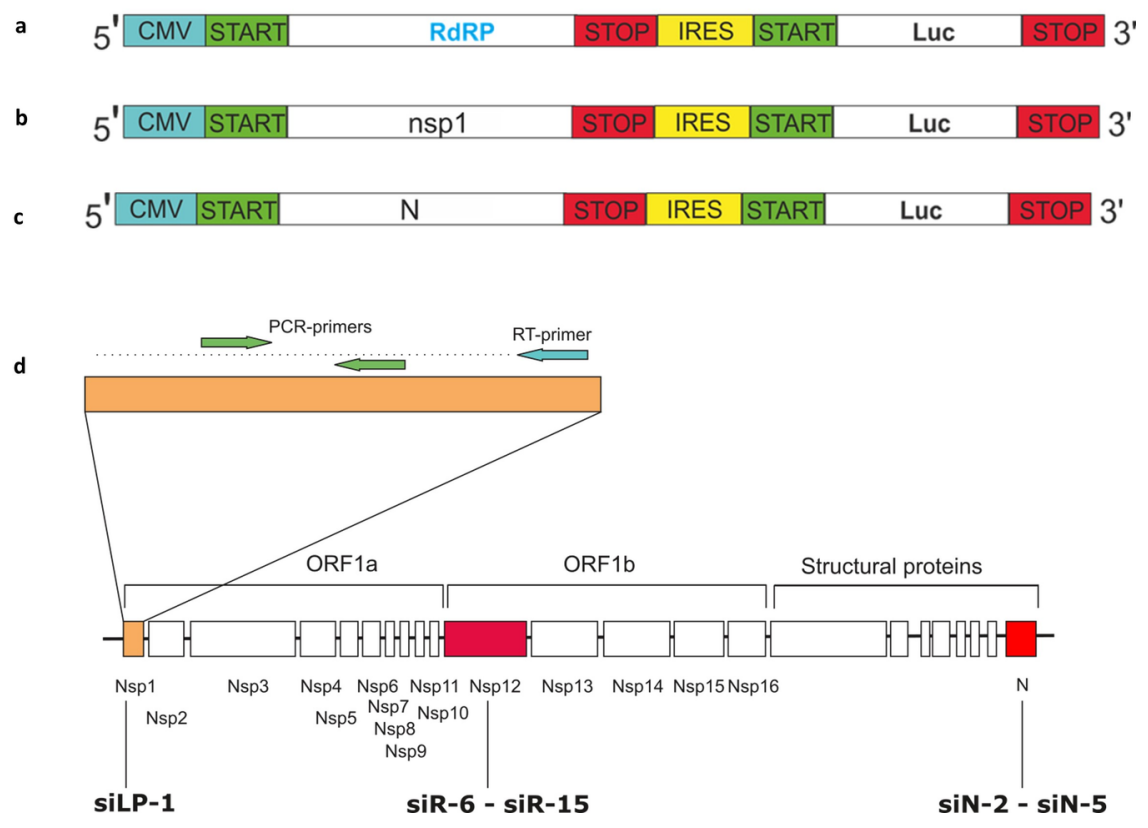
*/p value above- vs plasmid t/p value below- vs siGFP

for figures a-c
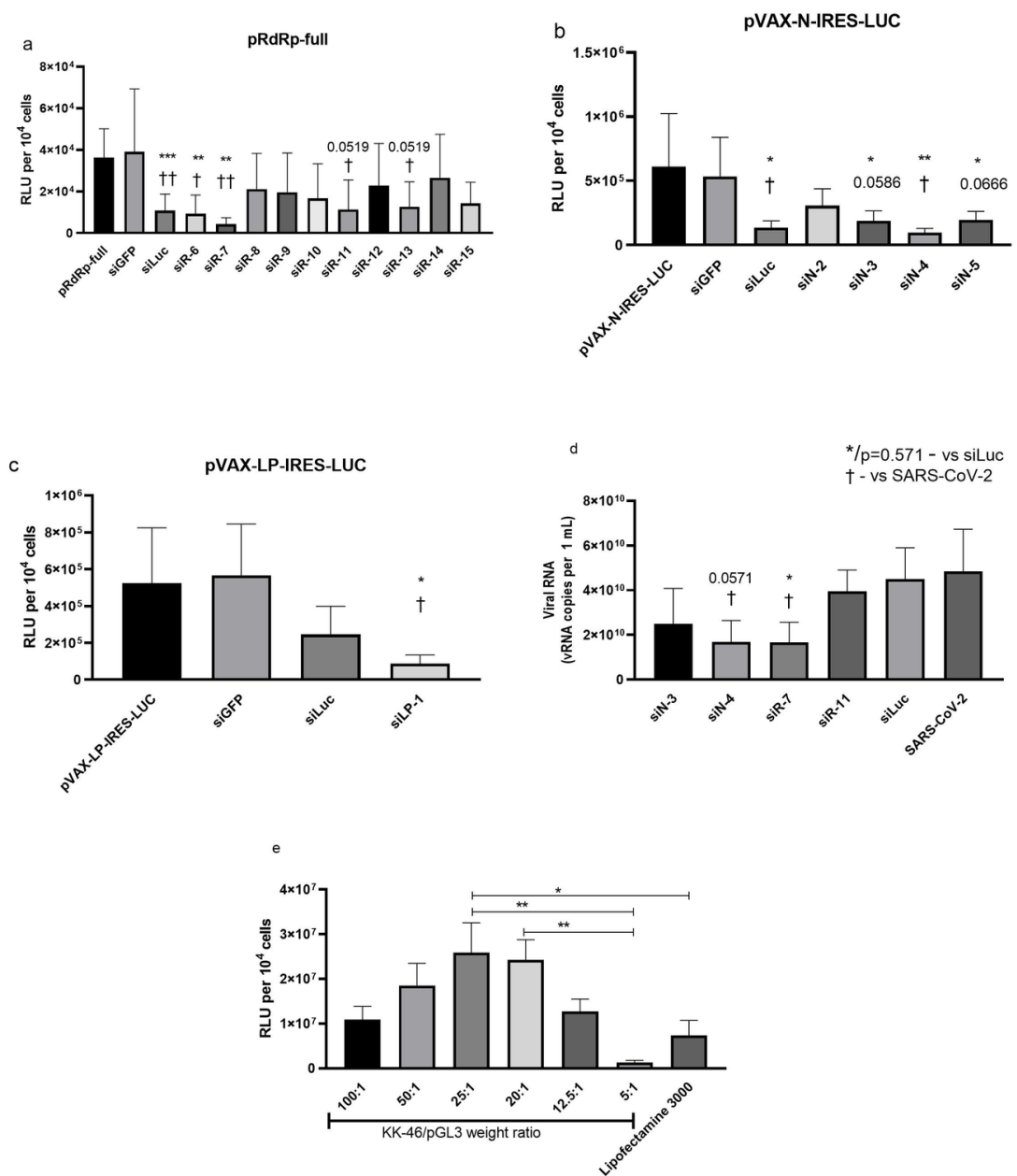


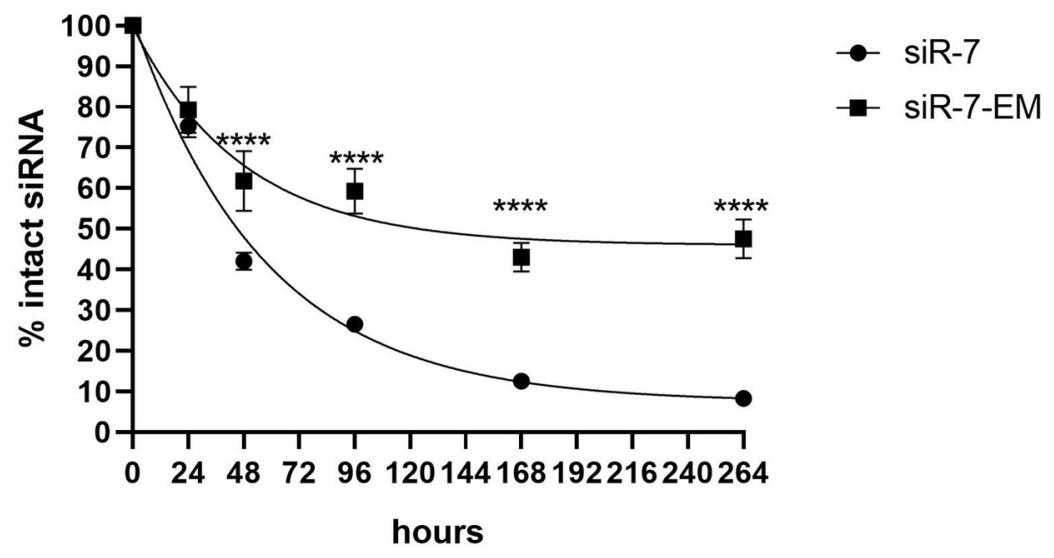

b siR-7 SiR-7-EM

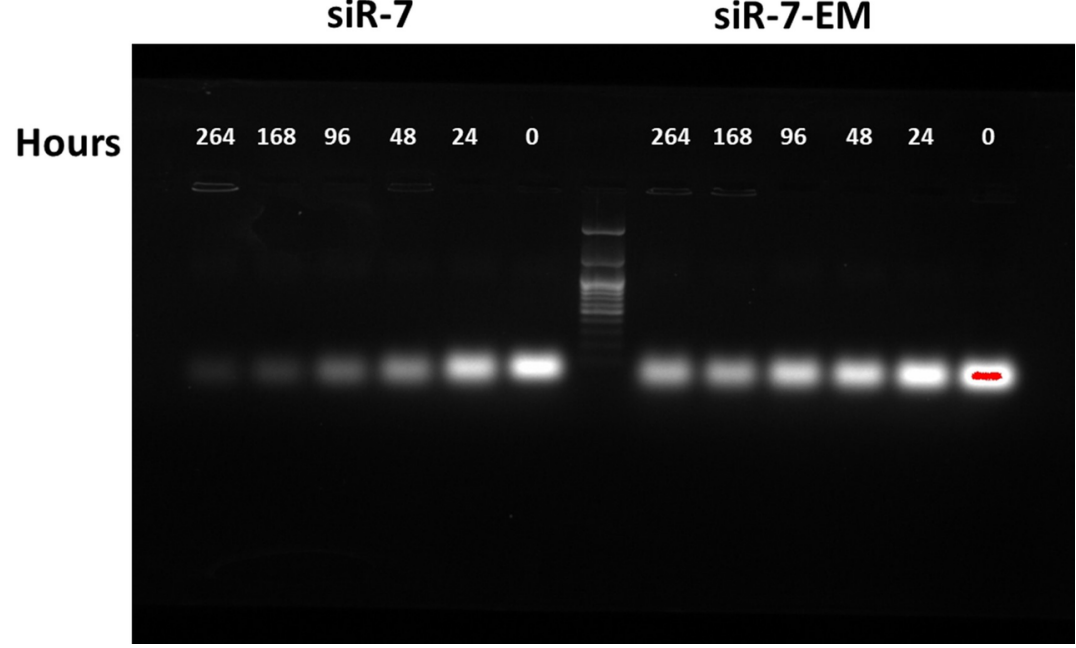




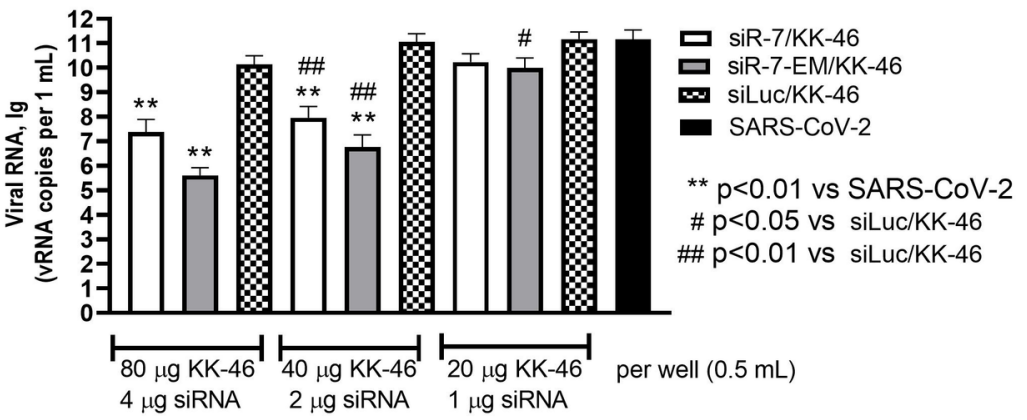

b Cell culture supernatants

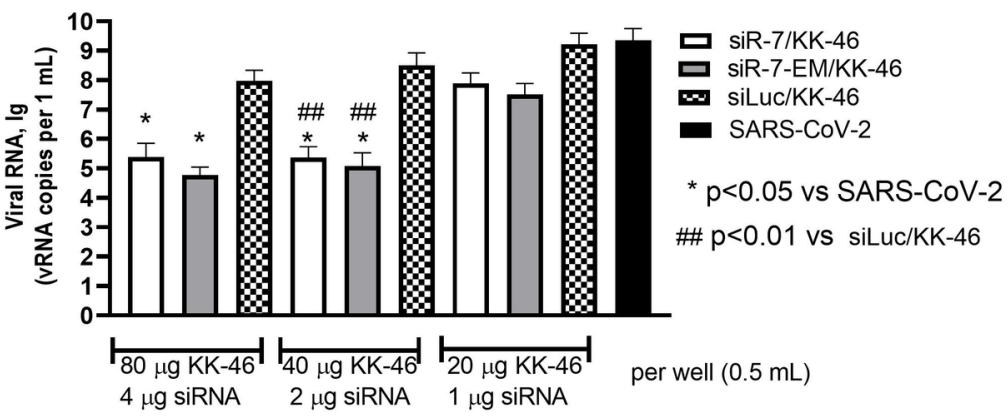



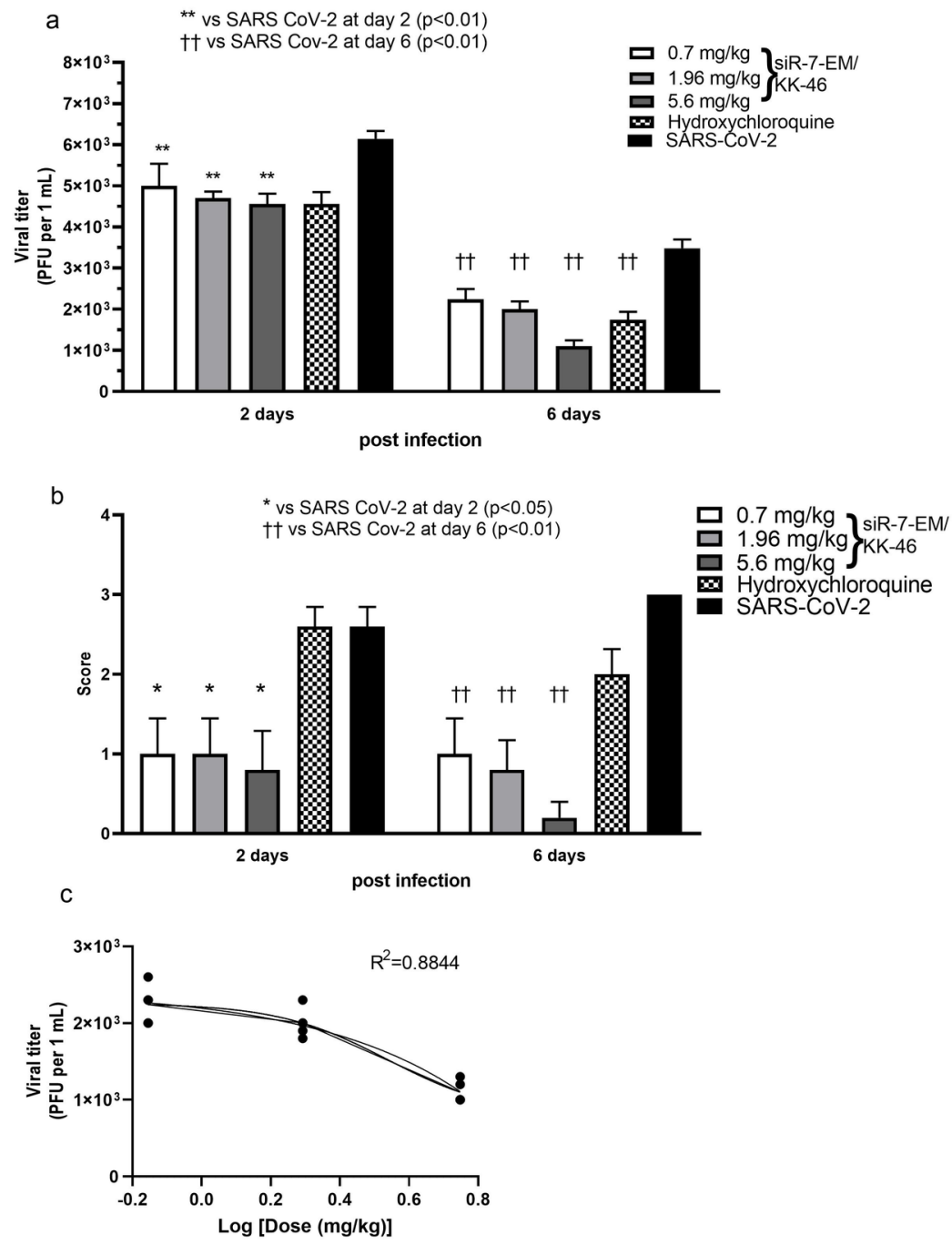


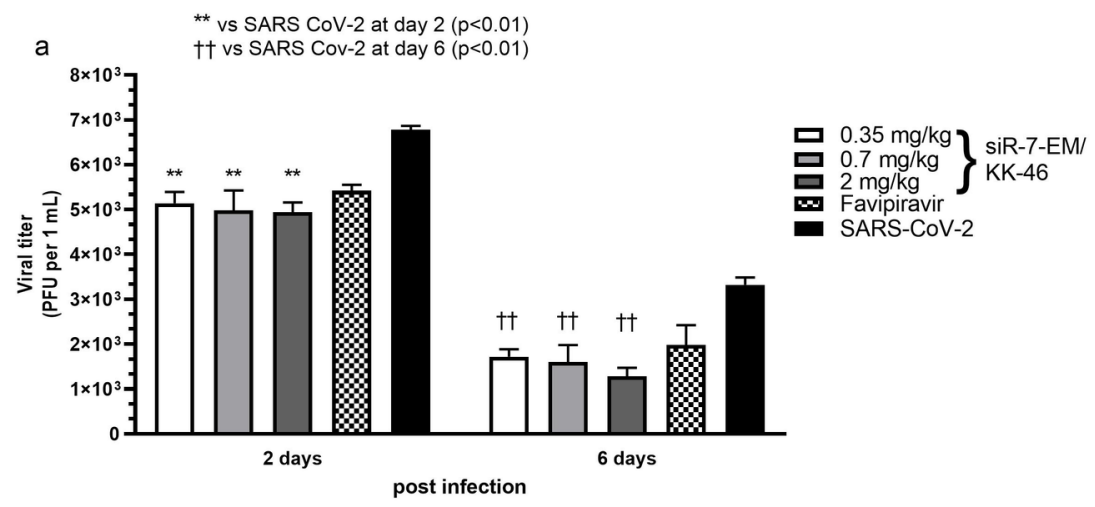

b

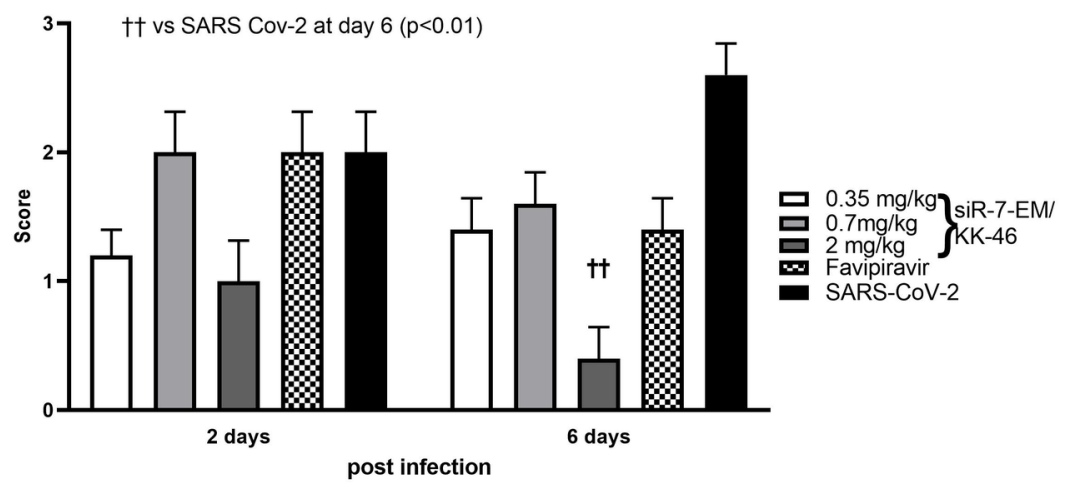

